\title{
Raúl Tuñón: zona de pasajes
}

GERALDINE ROGERS Universidad Nacional de La Plata - CONICET, Argentina / geraldine.rogers@gmail.com

\section{Resumen}

Propongo pensar los vínculos entre crónica y poesía como un rasgo fundamental y duradero de la escritura de Raúl Tuñón, orientada desde temprano a la exploración activa de formas reversibles e impuras que transitan entre lo poético y lo prosaico, el arte y la vida, lo real y lo imaginario. A partir de un corpus formado por poemas de los años 1930 y crónicas poco conocidas e inéditas fuera del soporte periodístico, considero su escritura como una zona de múltiples pasajes donde dos modalidades famosamente contrastadas por Mallarmé, poesía y reportaje, convergen y divergen, en dinámica tensión.

Palabras clave: Raúl González Tuñón / poesía / crónica / literatura argentina / 1930

\section{Raúl Tuñón: passages zone}

\section{Abstract}

In this article I propose to think about the links between chronicle and poetry as a fundamental and lasting feature of Raúl Tuñón's writing. It was oriented very early to the active exploration of reversible and impure forms that transit between the poetic and the prosaic, art and life, Real and imaginary. From a corpus of the 1930s, made up of poems of those years and chronicles little known and unpublished outside the journalistic support, I observe his writing as an area of multiple passages. In it, two modalities famously contrasted by Mallarmé, poetry and reportage, converge and diverge, in dynamic tension.

Key words: Raúl González Tuñón / poetry / journalism / literatura Argentina / 1930

Recibido: 30/5/2019. Aceptado: 1/7/2019

Para citar este artículo: Rogers, G. (2019). Raúl Tuñón: zona de pasajes. El taco en la brea, 10 (junionoviembre), 103-114. Santa Fe, Argentina: UNL. DOI: 10.14409/tb.vii10.8690 
Cuando yo tenía doce años, la maestra de $5^{\circ}$ grado, que se llamaba señorita Marcelina, nos pidió durante una de las lecciones de castellano que hiciéramos una composición singular: se trataba de convertir, en prosa, el poema de Antonio Machado «Orillas del Duero». No se crea que resultaba fácil para niños de diez a doce años poner en prosa un poema. No se crea tampoco que todas las maestras argentinas de hace veinte años eran capaces de una idea tan excelente o conocían al poeta de Castilla. (2011:149, subrayado en el original)

En este recuerdo de infancia de fines de la década de 1930 Raúl Tuñón agradece el conocimiento temprano del poeta Machado y el primer acercamiento por la poesía a un lugar del mundo donde, mientras escribe, suceden acontecimientos que serán cruciales en la historia del siglo, y donde él mismo participa de experiencias que son materia del libro Las puertas del fuego. Documentos de la guerra en España (1938). Pero además, la escena trae a la memoria un ejercicio de composición que consiste en pasar de una forma de escritura a otra, sin que ese ejercicio de translación se vea inhibido por la creencia en el texto definitivo o por preconceptos sobre la inferioridad de la prosa.

A partir de esa escena propongo pensar los pormenores de algo evidente: los pasajes e impregnaciones entre crónica y poesía son un rasgo fundamental de la escritura de Raúl Tuñón, orientada desde temprano a la exploración activa de formas reversibles e impuras que transitan sin reservas entre lo poético y lo prosaico, el arte y la vida, lo real y lo imaginario. Los vasos comunicantes enlazan modalidades contrastadas hace más de un siglo por Mallarmé cuando proclamó al poema como el único lenguaje capaz de sustraerse al universal reportaje, y al poeta como garante de la apertura de la lengua por su separación radical de la modalidad discursiva dominante de la modernidad, el periodismo. Más inclinada a las fronteras porosas que a las oposiciones tajantes, la escritura de Tuñón es una zona de múltiples pasajes donde poesía y reportaje convergen y divergen, en dinámica tensión. ${ }^{1}$

\section{El poeta reportero}

Como es sabido, la noción de modernidad estuvo desde siempre atravesada por el deseo de capturar el presente. En uno de sus célebres ensayos Baudelaire puso en el centro de atención la figura de un artista que enviaba sus bocetos al The Illustrated London News desde España o la guerra de Crimea. Un dibujante viajero atento a la metamorfosis diaria de las cosas exteriores, cuya velocidad de ejecución le permitía capturar lo vital, extrayendo lo eterno del flujo transitorio. Interesado por el mundo entero, quería saber, comprender y apreciar todo lo que ocurría en la superficie del globo. La curiosidad era su punto de partida; su pasión, fundirse con la multitud. El pintorcronista gozaba de lo numeroso, ondulante y fugitivo. Adoraba estar fuera de casa y se sentía en casa en todas partes. Su mayor afición era captar imágenes vivas en lo inestable.

De Baudelaire a Raúl G. Tuñón, numerosos artistas y escritores fueron pintores de la vida moderna e hicieron colaboraciones regulares en la prensa, activando las transferencias entre dos ámbitos cuyos intercambios fueron constante fuente de innovación.

Atraída por la realidad del mundo, la poesía se volvió permeable a lo contemporáneo. En pleno auge de la prensa de gran tiraje, los escritores modernos repudiaron una actividad «devoradora», «idiotizante» y «confusa» (Breton) donde reinaba el «mercenarismo de la opinión» (Desnos) y la «canalla escribiente» (Aragon). Pero el fantasma del periódico habitó el arte vanguardista: entre la atracción y el rechazo, muchos frecuentaron los dos ámbitos y sus textos fueron parte de una impregnación indudable. 
A mediados de la década de 1920, el diario más popular y exitoso de Buenos Aires había empezado a incluir en su equipo de redactores a varios jóvenes escritores nucleados en torno de las revistas Proa y Martín Fierro. Entre ellos, el poeta Raúl González Tuñón, que en 1925 se incorporó a Crítica donde escribió numerosas crónicas como «enviado especial». El viaje, fundamental en la vida y en la literatura de Tuñón, fue un feliz derivado de la práctica periodística. Ese vínculo temprano quedó fijado en multitud de poemas y en una anécdota contada muchas veces, según la cual el director del periódico, Natalio Botana, había detectado muy pronto las posibilidades del joven redactor al que convenía dejar «volar» lejos del escritorio para que trajera al diario sus notas de actualidad, llenas de curiosidad y espíritu de aventura. La afortunada conjunción potenció las inclinaciones de este explorador asombrado del mundo capaz de proveer de crónicas al periódico al mismo tiempo que creaba una obra poética que es entre otras cosas un documento de la historia del siglo (Aira).

Para una imaginación inclinada a la amalgama y la síntesis de los opuestos, documentar poéticamente el mundo era incorporar lugares, nombres o acontecimientos a partir de registros inéditos, distintos a los de un observador convencional: «Traigo la palabra y el sueño, la realidad y el juego de lo inconsciente, / lo cual quiere decir que yo trabajo con toda la realidad» (1987:31). En su recorrido, el poeta-cronista declina el lugar de observador privilegiado para proponer un juego de posiciones que rotan y dan lugar al intercambio de miradas, en un movimiento que modifica la perspectiva desde la cual observa: «Vamos a girar, por ejemplo, alrededor de La Rioja/y de esos rostros y esos paisajes que giraron a mi alrededor/hace algunos años/y que hoy se prolongan en la muerte de tantas fotografías perdidas» (31). No es solo el cronista quien se mueve, sino también las cosas frente a él:

Pasa una estación en el regazo del viento.

Jefe telégrafo teléfono carpeta mapa horario todo vuela.

Pasa un árbol con una escopeta

pasa un niño

pasa una canilla abierta

pasa un pequeño féretro blanco con manijas doradas. («Relato de un viaje», 1987:34)

No es solo el cronista quien mira y dice sobre los otros, también ellos lo ven pasar y sus palabras dan testimonio de su tránsito:

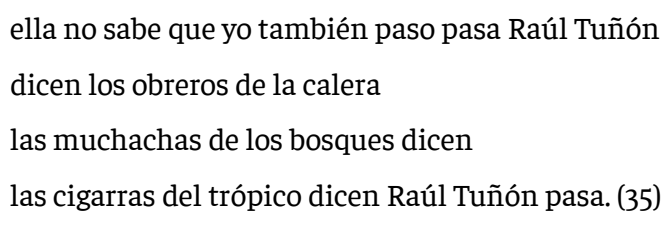

La centralidad de la posición de observador se pulveriza en un movimiento donde los roles - lo que mira y lo que es mirado, lo que habla y lo que es hablado - se alternan y con-funden. El ritmo de trenes y telégrafos impacta en el lenguaje poético, dando cuenta de la experiencia de la variedad a toda velocidad: «vertiginosamente me alejo venga viernes Renée/veletas pasan pasan caminos pasan torres venga viernes Renée». Pero incluso en ese vértigo acelerado el cronista-poeta no pierde la sensibilidad para percibir lo menor y preguntar por el destino de lo más pequeño («las cigarras cantan todo el verano y al invierno estallan/dónde irán a parar las cigarras de los trópicos/oh las cigarras enamoradas del día 
dónde irán a parar las cigarras/ después de cantar todo el verano»). Registra la precaria fugacidad de la vida individual al mismo tiempo que los grandes acontecimientos del presente en el devenir histórico:

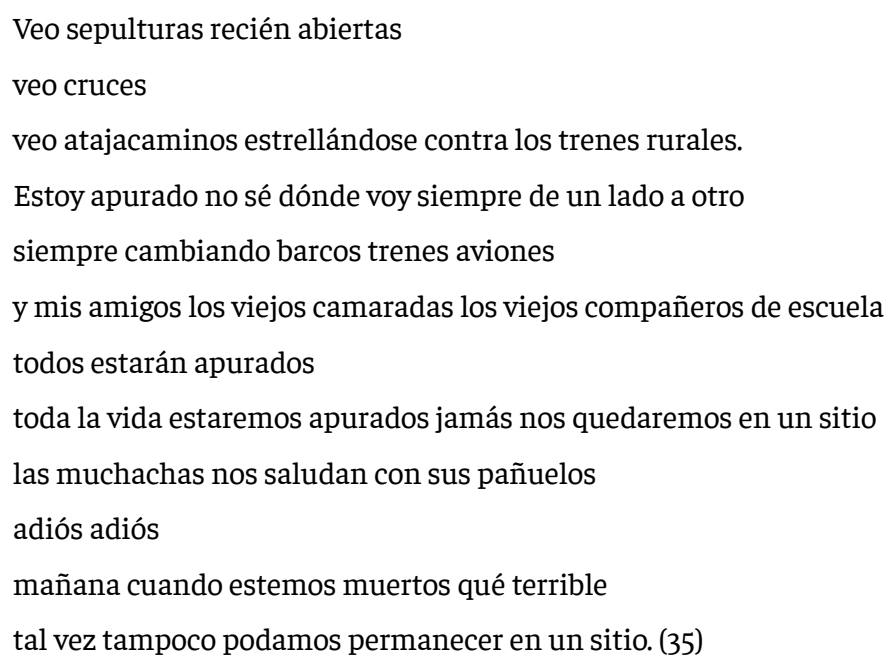

\section{Una poesía sin pureza}

Desde mediados de los años veinte Tuñón realizó crónicas periodísticas y en la década siguiente hizo varias series de reportajes (o crónicas de «enviado especial») sobre los inmigrantes desocupados en el puerto de Buenos Aires, sobre la Patagonia, la guerra del Chaco boreal y la situación española inmediatamente anterior a la guerra. En esos mismos años publicó La calle del agujero en la media (1930), Todos bailan (1935) y La Rosa blindada (1936), con poemas que reelaboran la experiencia como reporter en zonas alejadas. El conjunto es un corpus poético-periodístico cuyos materiales se complementan y disputan el tratamiento de la actualidad. Una composición publicada en octubre de 1935 en la revista Caballo verde para la poesía presenta una larga enumeración de cosas vistas y oídas al pasar por un cronista capaz de percibir la configuración poética del mundo en medio de las fuertes conmociones sociales:

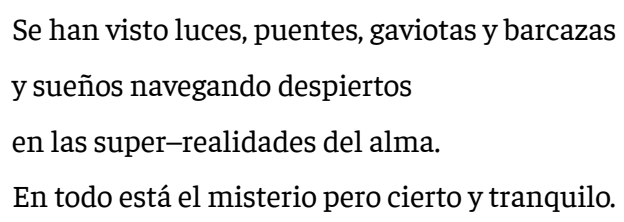

Hay árboles viajeros, lunas que dan la hora, espejos proyectando valles de terciopelo. Se han visto miriñaques saludando a la entrada de salones antiguos con los porteros muertos. Se ha visto el eco.

\section{(...)}

Hay caretas de gases, alarmas con incendios, amuebladas con crímenes, motines con auroras, bombas, espías, microbios de servicio secreto, rumor de yataganes y de banderas rojas. 
Hay bronca.

Hay la revuelta próxima que estallará de pronto

como la luz tan súbita que inventa una ventana.

Hay posibilidades para la poesía.

Hay mañana. («Poesía caminando», 1935)

La revista que publicó esos versos, dirigida por Pablo Neruda, manifiesta «una especie de atracción no despreciable hacia la realidad del mundo» que lleva a interesarse por una poesía «impura», "gastada», «arrugada», sucia, corporal, radicalmente heterogénea. ${ }^{2}$ Solo un año antes Walter Benjamin había dejado constancia de una percepción similar acerca de los cambios estéticos en esa época intensa en que las categorías literarias convencionales perdían fuerza y emergía una escritura vital que transitaba entre lo poético y lo prosaico (2009:303). La escritura de Tuñón comparte esa orientación impura con la de otros artistas ${ }^{3}$ que buscaban articular vanguardia estética y política, transformando la literatura en un dispositivo crítico no solo por sus temas sino sobre todo por sus operaciones formales. Una de ellas consiste en recrear los estereotipos estandarizados, con modalidades cercanas al montaje dadaísta y surrealista, inscribiendo el discurso social hasta volverlo extraño y, sin separarse del flujo discursivo común, hacer ver y hacer escuchar lo no visto y no oído todavía: «Cuando Rimbaud gritó: “Cambiad la vida”, se estaba ante las puertas de la Comuna. El poeta es el primero en sentir el acontecimiento» (2011:145). La función comunicativa y poética no dejan de entrelazarse. Una frase ordinaria hace surgir en el lenguaje «eso desconocido que se convoca para darle un sentido y una rima nueva a la vida colectiva» (Rancière:20). La noticia o el titular emergen como fragmentos de historia o de actualidad enrarecida: «¿Flor Intrencherado? ¿Dónde ha leído ese nombre? ¿Quién es? Ah, un general filipino. ¿Qué será del general filipino Flor Intrencherado?» (1935).

La poesía incorpora material documental pero elude la sumisión a la realidad exterior y visible, fomentada por el uso rutinario de textos e imágenes en la prensa. Frente a la «actitud realista» ${ }^{4}$ se instala en el entresueño, acoplando imaginación y vigilia de lo real («lo que pasa y pasó y aquello que vendrá/se unen finamente en el sueño del tiempo» (González Tuñón, 1965). Aunque en menor medida, también la crónica resulta infiltrada por cierto lirismo que explora la zona lindante entre la palabra y el sueño, la realidad y el juego de lo inconsciente: «Yo he volado sobre la Patagonia y he visto golfos, ríos, bahías, valles. Llevaba un pequeño mapa y más me alegraba el estudio de éste que la contemplación de la tierra, grandota para mi mirada, fugaz, en el vértigo del avión. En todo, lo más interesante es el límite. Lo real limita con lo fabuloso». ${ }^{5}$

En Todos bailan. Los poemas de Juancito Caminador ${ }^{6}$ crónica y poesía se entrecruzan con particular intensidad. «Historia de veinte años» repasa la vertiginosa transformación del mundo contemporáneo a partir de la guerra de 1914. «Los negros de Scottsboro» trata un suceso presente en los diarios de 1931 —nueve adolescentes víctimas del racismo habían sido sentenciados a pena de muerte en Alabama - en versos que reenvían a las invocaciones y ritmos del blues y el negro spiritual. Otro acontecimiento de ese mismo año, la ejecución del anarquista italiano Severino Di Giovanni en Buenos Aires, irrumpe al final de «Cosas que ocurrieron el 17 de octubre», crónica poética de un día ordinario. El gastado lenguaje periodístico reaparece en imágenes 
descompaginadas, que reelaboran la experiencia de lo contemporáneo. Recortes de noticias policiales, acontecimientos bélicos e información política - la noticia sobre una bomba colocada en el Banco de Boston o la de un tranvía caído al Riachuelo, que el propio Tuñón había cubierto como reportero de Crítica - emergen como fragmentos desprendidos, entre enumeraciones que escapan a la cronología, abriendo paso a un ensamblaje de imágenes azaroso e iluminador:

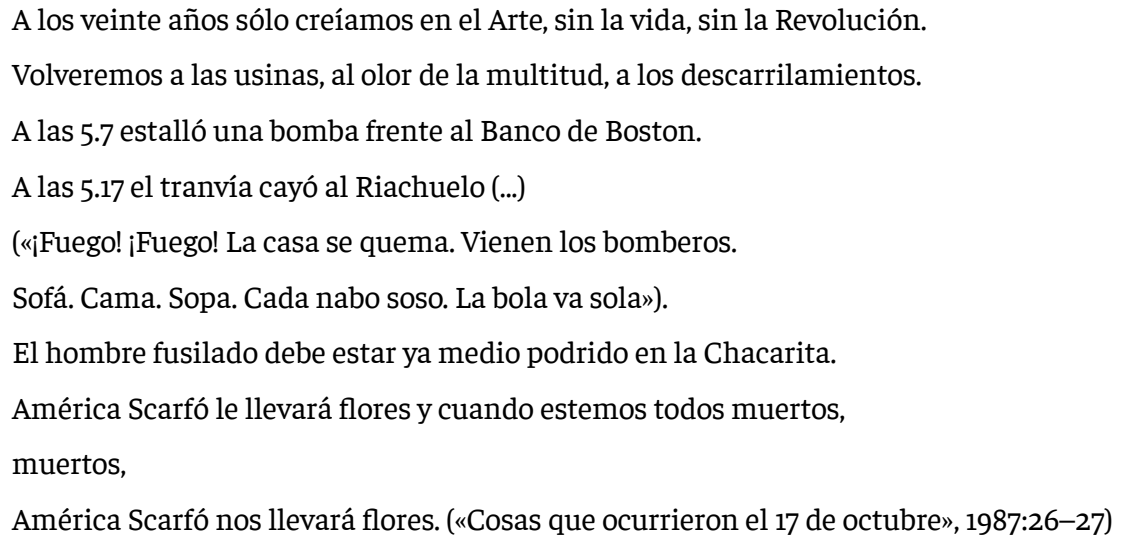

Tuñón hizo del universal reportaje un elemento fundamental de su poética: la noticia y el apunte de viaje integran la masa de materiales con la que compone su obra. Sus poemas-reportajesintervenciones traspasan las fronteras entre el lenguaje del arte y el de la vida ordinaria, en una refundición acorde a las transformaciones de una época tumultuosa. El adentro y el afuera se mezclan, lo nuevo se encuentra con lo viejo. El mundo es percibido como un gigantesco amontonamiento de ruinas y rascacielos, donde las cosas se destruyen y renuevan sin pausa, en un revoltijo para el asombro:

Mi vida está en los puertos del mundo mirando países,

barajando pañuelos de inútiles partidas e imposibles retornos.

En las viejas calles de las ciudades muertas

en donde el pasado es algo tan vivo y tan presente y tan humano (...)

$Y$ en caminar y en nada de todas las ciudades,

en las usinas, en los rascacielos y en las plazuelas

como la de Contrescarpe.

En los barcos ya grávidos de mares y de vientos

y en los grandes expresos que asombran casas chatas

y sólo se detienen en los altos países (...)

Y en mi esperanza de no sé qué fiebre, qué pasión, qué dolor

que un día vendrá para salvarme.

Esperar, esperar en una esquina,

encender un cigarrillo

y escuchar con asombro, con miedo, con nostalgia

la música amontonada del mundo. («Recuerdo de A. O. Barnabooth», 1987:36-37) 
Mejor que en un relato lineal y abstracto, la historia de dos décadas es recuperada por un collage caótico de titulares de diario. Los temas y la retórica de la crónica infiltran el poema pero no reproducen los modos convencionales de ver el mundo. El montaje poético-documental repasa la línea del tiempo solo para desmantelar la sucesión de hechos y personajes, reconfigurando a la vez la imagen del presente:

1919, 1920, 1921, 1922, 1923, 1924, 1925.

Un temblor histérico corre por la espina dorsal del mundo.

Una falsa prosperidad se instala en las ciudades y en los campos.

Prospera la cadena con Ford, Citroen, Coty, Fiat.

¡Atención al cinematógrafo, al arte nuevo! («Historia de veinte años», 1987:16)

El poema-crónica pone a la vista anacronismos y supervivencias — «Fíjate cómo se amontona la historia,/ cómo muere y renace todo,/ cómo los que creíamos vivos han desaparecido,/ cómo los que creíamos muertos están presentes» (13) - y muestra la dimensión descomunal de los desastres: «Centenares de hombres se ahogan en los submarinos hundidos./ ¿Qué importa una catástrofe después del Marne, Jutlandia y Verdún?» (17). Interrumpe la cadena de acontecimientos, los recorta y reencuadra para desentumecer la atención con imágenes nuevas: «¿Quién no está despierto, quién no permanece atento en la noche del caos?» (17). A veces el poema-crónica se transforma en intervención militante y toma partido señalando una dirección en medio del desconcierto: «Oh, no me olvido de Rusia/ allí está la libertad en preparación, allí está la dignidad del hombre...». Puede re-montar un par de décadas o un solo día, imitando el lenguaje torpe del periódico para volverlo extraño y producir un efecto de distancia:

\footnotetext{
El automóvil se lanzó a la carrera con un ronquido impresionante.

El intendente visitó esta tarde los barrios obreros húmedos y rencorosos (...)

Me bebo un seco de gordon, bailo un blues, me enamoro de algunas chimeneas

y me río de los millonarios.

El pobre hombre dijo cuatro palabras y cayó muerto, acribillado.

El coronel entregó personalmente cinco pesos a cada soldado.

Le habían dicho: «mañana, al alba, será usted fusilado».

Los otros condenados aullaron agarrados a las rejas.

Tres niñas de la sociedad van a ser presentadas al Príncipe de Gales.

El parque amaneció cubierto de preservativos.

Josefina II ha pasado recién como un silbido.

Se acercará al muelle y las lindas muchachas bajarán, de sombrilla. («Cosas que ocurrieron el 17 de octubre», 1987:27)
}

Las imágenes hacen descarrilar el tiempo sucesivo para dar cuenta de una historia en demolición, que es también una historia viva en plena fermentación: «todo se está pudriendo,/ lo más flamante se pudre y se viene al suelo con estrépito./ Las catedrales, la música, la pintura, todo huele a podrido» («Historia de veinte años», 1987:16).

Los poemas de Tuñón desarman el montaje falsificado de los periódicos recomponiendo por su 
cuenta los elementos ofrecidos por la prensa. Para hacer una poesía, decía el manifiesto dadaísta en 1918, bastaba tomar un periódico y una tijera, escoger un artículo de longitud acorde al poema deseado, recortar las palabras, poner en un recipiente y mezclar (Tzara 1968; G. Tuñón, 1976). En 1924 el surrealismo retoma la idea: «cualquier medio es bueno para obtener de ciertas asociaciones la instantaneidad requerida. Los papeles pegados de Picasso y de Braque tienen el mismo valor que la introducción de un lugar común en el desarrollo literario del estilo más pulido. Hasta se vuelve lícito denominar POEMA al resultado obtenido por la reunión lo más gratuita posible (conservando, si se quiere la sintaxis) de títulos y fragmentos recortados de los periódicos».? El periódico era la quintaesencia de la modernidad: heterogéneo, caótico, siempre a la caza de novedad. Era también la modalidad discursiva dominante, la más eficaz para crear un tiempo colectivo. La de mayor alcance para permear la experiencia cotidiana, aplanar el lenguaje hasta dejarlo exhausto y generar distorsiones capaces de embotar por completo la percepción. Pero «en el escenario de la degradación total de la palabra (es decir, el periódico) se incuba[ba] la salvación de la palabra»: el poema podía asimilar esas distorsiones ${ }^{9} \mathrm{y}$ devolverlas multiplicadas.

\section{Ejercicios de composición}

Varios poemas de la década de 1930 elaboran la experiencia narrada en las crónicas periodísticas. «Blues de Rio Gallegos», fechado al pie «Patagonia, 1932», retoma imágenes y paisajes afines a la serie «El lejano sur» escrita para Crítica. «La pequeña brigada» lleva la inscripción al pie «Chaco Boreal, 1932» y agrupa estrofas que funcionaban como epígrafes de una serie publicada en el diario. Los poemas procesan la experiencia en zonas alejadas, visitadas con ojos y oídos de reporter para escribir sobre cuestiones de actualidad.

Esos pasajes e impregnaciones mutuas están en la escritura de Tuñon desde temprano. Una nota de 1930, recordada más tarde como «la crónica más conmovedora, una crónica monumental diría yo, pues participamos varios», se originó en un suceso trágico que «conmovió a Buenos Aires como un largo temblor, cuando un tranvía lleno de obreros cayó al Riachuelo en una madrugada atroz». Varios enviados del diario se trasladaron al lugar para cubrir el suceso. Raúl Tuñón fue el encargado de redactar el recuadro que condensara una imagen o anécdota significativa: «Tomé como base lo que me contó un cabo de prefectura: entre los muertos había un pibe, un obrerito de diez $u$ once años y en el bolsillo de su chaquetón encontraron un pequeño paquete con un sándwich de milanesa, seguramente preparado por su madre» (Salas:62). La imagen recogida de boca de un testigo volvió años después en un poema, como un flash instantáneo entre jirones desgarrados de actualidad: «Volveremos a las usinas, al olor de la multitud, a los descarrilamientos./ A las 5.7 estalló una bomba frente al Banco de Boston./ A las 5.17 el tranvía cayó al Riachuelo./» (1987:26). Décadas más tarde, la imagen del obrerito muerto con su sándwich permanece intensa en los canales de la memoria:

\footnotetext{
Los amigos estaban allí; la noche, el humo

—su pequeño país de ansias y sueños vagos-.

Los poemas ya escritos y los que se agitaban

detrás de la vigilia; los últimos cocheros;

Pelito Verde, el Sábalo, canillitas; bohemios

sin melena; el buraco
} 
en la pared —un desvaído mapa-

desde donde salía el plato fuerte

y el vino del invierno.

(Y después un tranvía cayó al Riachuelo...

En el saco de pana, el obrerito,

llevaba un sándwich de carne fiambre

y una figura de calcomanía). («El puchero misterioso», 1975)

Los ejemplos abundan. El poema «Dos historias de niños» de La Rosa Blindada recrea poéticamente un evento de la serie periodística escrita por Tuñón para un magazine ilustrado. En la crónica, la voz «directa» de un testigo sintetiza el núcleo narrativo:

-Yo mismo los vi. Cuando la revolución estaba ya perdida y los guardias, mientras las tropas asediaban las ciudades, ganaban los puntos estratégicos de la cuenca, cuatro niños mineros se apoderaron de las armas de sus mayores caídos de una camioneta carbonera. Salieron sin rumbo, enloquecidos, disparando sus armas contra los guardias que encontraban. Conocían muchos de los recodos de la cuenca. Hay en Asturias centenares de estos niños trabajadores que, mientras sus padres bajan al fondo de las minas, empiezan el oficio, realizando pequeños trabajos en la superficie. La camioneta no anduvo mucho tiempo. Los cuatro niños fueron alcanzados por los disparos de los guardias. Yo los ví, cerca de Mieres, cuando pasaba, fugitivo, buscando un escondite. Entre el lodo y la sangre, entre las piedras y la camioneta destruida, apretaban contra sus débiles pechos las carabinas de sus padres... (1936b)

Los niños mineros alcanzados por los disparos de los guardias reaparecen en el poema, pero ahora el tiempo de la crónica se expande y se transforma en tiempo subjetivo («hacia la mitad de octubre o cuando en las hondonadas del viento se ahoga el día intensamente pálido») y lleva al núcleo sensible del acontecimiento. El poema rescata lo menor («Cuando ya han muerto todas las mariposas de los bosques pequeños y los montes azules») y cede a la dimensión onírica la captación profunda del presente y de la historia:

Hacia la mitad de Octubre o cuando la llovizna de la hulla cae sobre las vías y una linterna roja arroja un rayo frío sobre la marquesina que cubre la osamenta del verano.

Cuando ya han muerto todas las mariposas de los bosques pequeños y los montes azules.

Cuando comienzan a murmurar las brújulas con sus gallos agudos y el esqueleto de un grillo nos conmueve.

Cuando en las hondonadas del viento se ahoga el día intensamente pálido.

Entonces ellos ingresan a la sombra, ellos viajan al fondo de la tierra, ellos bajan al fondo del otoño.

Arriba, sobre la camioneta, los niños buscadores de oro negro los ven pasar, turno que abre la noche.

La camioneta arranca con rumbo a la voz baja de las cocinas desoladas, y ruedan las cabezas de los niños sin sueños, bajo las viejas lunas del carbón, oh, rayos. (1936a:41)

Los rasgos formales del poema — fragmentación, desarticulación sintáctica — traducen los efectos devastadores de la violencia, con imágenes afines al estallido visual que un año más tarde pintará Picasso, tras el bombardeo de Guernica. La longitud creciente del verso parece traducir 
una experiencia desmedida, manifestando el exceso brutal con un amontonamiento caótico de imágenes:

Lo he oído contar a algún sobreviviente y supe que a la orilla de los niños sangrientos, reventados, a la orilla de las madres con gusanos, palomas y raíces, piedras y llamas, agujas y navajas, oh, madres de la tierra del carbón y del oro, los guardias fusilaban a los muertos. (1936a:41)

La guerra civil española, iniciada meses después de publicarse La Rosa Blindada, intensificará los pasajes entre crónica y poesía (Binns; Miranda; Cano Reyes 2017a y b). Los ejemplos son numerosos y muestran un rasgo duradero en la escritura de Tuñón, que se remonta a los años previos y continúa después. Así lo piensa en esta autofiguración que abre La veleta y la antena (1969):

\begin{abstract}
A veces el poeta inventa, incluso lleva la fantasía al límite del absurdo (...); inventa y descubre países, digamos, en la vasta geografía del canto. Pero a veces trata de conversar con su época, de glosarla, y en algunos casos suele desbordarla. Es cuando la poesía deviene una especie de crónica, ya sutil, ya descarnada, de su tiempo. En ocasiones el enlace de lo uno y de lo otro supone el equilibrio entre el sueño y la acción que el genio de Baudelaire previó para nuestro siglo divagador y apasionante... (9)
\end{abstract}

\section{Notas}

1 Lo que sigue es adelanto del libro Raúl González Tuñón, poesía y reportaje.

2 «Así sea la poesía que buscamos, gastada como por un ácido por los deberes de la mano, penetrada por el sudor y el humo, oliente a orina y a azucena, salpicada por las diversas profesiones que se ejercen dentro y fuera de la ley. Una poesía impura como un traje, como un cuerpo, con manchas de nutrición, y actitudes vergonzosas, con arrugas, observaciones, sueños, vigilia, profecías, declaraciones de amor y de odio, bestias, sacudidas, idilios, creencias políticas, negaciones, dudas, afirmaciones, impuestos» (Sin firma, «Sobre una poesía sin pureza», 1935).

3 El autor de Manhattan Transfer (1925) y la trilogía USA: (1930-1936) está entre las presencias explícitas en diversos textos de G. Tuñón.

4 «Hay que instruir un proceso contra la actitud realista» (Breton).

5 «El gran artista, el verdadero artista, puede con la arcilla más tosca, realizar la obra divina. Nada más lleno de sutiles misterios, de reales milagros, de cosas fabulosas, que la realidad misma. Gorki decía que lo difícil es saber percibir lo que de fabuloso tiene la realidad. (...) El Greco hizo el plano de la ciudad de Toledo con todas las cosas vistas de frente. No se puede negar que trabajaba con la realidad, pero en combinación con lo fabuloso» (González Tuñón, 1932a). «De pronto el sabio, metido en la soledad de su gabinete, en la rebusca de maravillosas sutilezas, realiza una aventura más intensa que la del explorador que va sobre la tierra y bajo el cielo, en busca de otra tierra y otro cielo, que, al fin de cuentas, es la misma cosa, con diferente clima» (González Tuñón, 1932b).

6 Se trata de un libro de rasgos inusuales, editado con el sello de la Editorial Don Quijote de la localidad de Azul. A medio camino entre el libro, el periódico y la hoja suelta, Todos bailan parece querer escapar a la anticuada mediación del libro para asimilarse a las formas modestas, más propicias a la dispersión callejera y al intercambio fluido de las letras en el espacio público, como ocurría con las hojas periódicas de las que algunos de esos poemas provenían. Cfr. Rogers.

7 También Brecht ensayó una relación crítica con la actualidad a través de montajes poético-documentales con recortes de prensa arrancados de su contexto discursivo e ideológico inicial. Cfr. Didi-Huberman.

8 Cfr. Benjamin, 2009 y Tretiakov.

9 «Respondiendo a la distorsión con la distorsión multiplicada (...) que nuestra voz se oiga todavía y pueda romper el cerco 
de los lenguajes dominantes de la globalización, de la cultura de los llamados medios de comunicación alienando a su público, ese público donde los individuos no son nada. El solo intentarlo ya es heroico» (Lamborghini:69).

\section{Referencias bibliográficas}

Aira, C. (2001). Diccionario de autores latinoamericanos. Buenos Aires: Emecé/Ada Korn.

Alle, M.F. (2015). Imágenes de escritor de Raúl González Tuñón (1930-1970): vínculos entre literatura y política partidaria. Rosario: Universidad Nacional de Rosario (tesis de doctorado).

Baudelaire, Ch. (2011). Baudelaire journaliste. Articles et chroniques (choisis et presents par Alain Vaillant). Paris: Flammarion. (2014). El pintor de la vida moderna. Buenos Aires: Taurus.

Benjamin, W. (1989) [1931]. El carácter destructivo. Discursos interrumpidos I. Buenos Aires: Taurus. (2009) [1934]. El autor como productor. Obras II/vol. 2. Madrid: Abada.

Binns, N. (2012). Argentina y la guerra civil española. La voz de los intelectuales. Madrid: Calambur.

Boucharenc, M. (2005). L'Universel Reportage. Mélusine XXV, Cahiers du Centre de Recherche sur le Surréalisme.

Breton, A. (2001). Segundo manifiesto del surrealismo (1930). En Manifiestos del surrealismo. Buenos Aires: Argonauta, 71-154.

Cano Reyes, J. (2017a). Fiebre y épica: Raúl González Tuñón, corresponsal de la Guerra Civil Española. Anales de literatura Hispanoamericana, (46), 239-260.

(2017b). La imaginación incendiada. Corresponsales hispanoamericanos en la Guerra Civil Española (palabras preliminares y colofón de Niall Binns). Barcelona: Calambur.

De Micheli, M. (1968). Las vanguardias artísticas del siglo veinte. Córdoba: Editorial Universitaria de Córdoba.

Didi-Huberman, G. (2008). Cuando las imágenes toman posición. Madrid: Machado libros.

Ferrari, G. (2006). Raúl González Tuñón periodista. Buenos Aires: Centro Cultural de la Cooperación Floreal Gorini.

González Tuñón, R. (1932a). «Lo real y lo fabuloso». Crítica, 27 de diciembre. (1932b). Más sobre lo real y lo fabuloso. Crítica, 29 de diciembre. (1935). Poesía caminando. Caballo verde para la poesía, (1).

(1936a). La rosa blindada. Homenaje a la insurrección de Asturias y otros poemas revolucionarios. Buenos Aires: Federación Gráfica Bonaerense.

(1936b). La primera bomba en el corazón de la cuenca. El semanario, 29 de abril. (1965). Poemas para el atril de una pianola. Buenos Aires: Horizonte. (1969). La veleta y la antena. Buenos Aires: Buenos Aires Leyendo. (1975). El puchero misterioso. A la sombra de los barrios amados. Buenos Aires: Lautaro. (1976). La literatura resplandeciente. Buenos Aires: Boedo-Silbalba. (1987) [1935]. Todos bailan. Los poemas de Juancito caminador. Buenos Aires: Libros de Tierra Firme. (2011). La muerte en Madrid. Las puertas del fuego. 8 documentos de hoy (prólogo y notas de Julia Miranda). Rosario: Beatriz Viterbo.

Lamborghini, Leónidas (2010). Mezcolanza. A modo de memoria. Buenos Aires: Emecé.

Miranda, J. (2016). Montajes: inventario del desastre. Frenética armonía. Vanguardias poéticas latinoamericanas en la Guerra Civil Española. Rosario: Beatriz Viterbo, 109-119. 
Rancire, J. (2011). Política de la literatura. Buenos Aires: Libros del zorzal.

Rogers, G. (2015). Raúl Gonzalez Tuñón desencuadernado. Políticas de la literatura, entre el libro y las publicaciones periódicas. Aletria, (25), 229-242.

Salas, H. (1975). Conversaciones con Raúl González Tuñón. Buenos Aires: La Bastilla.

Sheringham, M. (2006). Everyday Life. Theories and Practices from Surrealism to the Present. New York: Oxford University Press.

Trétiakov, S. (1977). Dans le Front Gauche de l’Art. París: Maspero.

Sin firma (1935). Sobre una poesía sin pureza. Caballo verde para la poesía, Nro. 1, octubre.

Tzara, T. (1968). Tzará, «Manifiesto sobre el amor débil y el amor amargo». En De Micheli, Las vanguardias artísticas del siglo veinte. Córdoba: Editorial Universitaria de Córdoba. 